\title{
CIENCIA Y POLÍTICA. LOS BOTÁNICOS MARIANO LAGASCA Y SIMÓN DE ROJAS CLEMENTE EN LAS CORTES DEL TRIENIO LIBERAL*
}

\author{
por \\ J. Luis MALDONADo Polo \\ Instituto de Historia, CSIC
}

RESUMEN: Con este estudio pretendemos contribuir al mejor conocimiento de un prácticamente desconocido capitulo de la historia de la ciencia española. Lo haremos a través del seguimiento de las actuaciones como diputados en las Cortes españolas de dos destacados botánicos durante el Trienio Liberal. Por consiguiente intentaremos dar a conocer los impulsos políticos que les motivaron, sus posiciones ante las cuestiones más relevantes que se debatieron en el parlamento en relación con los problemas que afectaban a la actividad científica, sin olvidar otros aspectos directamente relacionados, dentro del marco de los acontecimientos políticos que marcaron la vida cotidiana en el período sugerido. Todo ello basado fundamentalmente en los materiales procedentes de la fuente impresa: "Diario de sesiones de las Cortes».

Palabras Clave: Cortes. Trienio Liberal. Diputados. Ciencias naturales. Botánica. Agricultura. Instrucción pública.

ABSTRACT: This study aims to contribute to our knowledge of a practically unknown chapter in the bistory of Spanish science by following the actions of two leading botanists as representatives in the Cortes during the Trienio Liberal (1820-1823). It will examine the political impulses that motivated them, and their positions regarding the relevant issues debated in the Cortes concerning the problems that affected their scientific activity, without overlooking related matters in the political sphere which affected daily life in this period. All of this is based fundamentally on materials from the printed source "Diario de sesiones de las Cortes».

* Este artículo forma parte del proyecto de investigación BHA2000-1230, (MCYT) y del titulado "Historia del Real Jardín Botánico de Madrid: el período romántico», financiado por la CAM, dentro del programa de formación de personal investigador, 2000-2003.

Hispania, LXIII/3, núm. 215 (2003) 1031-1056 
KEY WORDS: Cortes. Trienio Liberal. Parliamentary representatives. Natural science. Botany. Agriculture. Public education.

\section{CONSOLIDACIÓN DEL RÉGIMEN CONSTITUCIONAL. LOS CIENTÍFICOS EN EL TRIENIO LIBERAL}

La Revolución española de 1820 estuvo influenciada por la Ilustración que no desapareció de momento, sino que se transformó con otro contenido. España es naturalmente todavía en estas fechas un país feudal y lo seguirá siendo todavía durante mucho tiempo, en lucha con corrientes renovadoras, siempre en frontera entre la Edad Media y las primeras manifestaciones del mundo moderno. Todo parece viejo, la monarquía, caduca y sin prestigio, la Iglesia, reaccionaria, lo es más todavía porque teme las ideas desamortizadoras, los aristócratas, los palaciegos, los financieros,, etc., se arrepienten de su pasado ilustrado, de manera que si los reformistas de finales del XVIII eran modernizadores, en 1820 fueron reaccionarios. Lo nuevo ahora en esta España contradictoria consistirá en la reclamación de derechos, de modo que la lucha de clases se traslada al ámbito constitucional.

En 1820 se instauraron en España las pautas que siguió la revolución liberal durante buena parte del siglo XIX: las conjuras y pronunciamientos y su sustento en la legislación de un cambio de rumbo en Madrid. Y en efecto durante el Trienio Liberal se inició este proceso, de manera que entre la insurrección militar de Riego (1 de enero de 1820), apoyada por la sublevación en provincias, y la subsiguiente aceptación y jura por el rey de la Constitución de Cádiz ( 9 de marzo y 9 de julio respectivamente), se abrió para España la segunda época constitucional hasta el 1 de octubre de 1823, en que quedó otra vez establecido el régimen absolutista fernandino.

Las primeras Cortes del Trienio, aunque moderadas, tuvieron como fines alcanzar lo que no pudieron conseguir las primeras de Cádiz y legislaron para dar continuidad a la primera época constitucional, en el sentido de la modernización del Estado y la Administración. Tuvieron su base legal en los distintos decretos que se aprobaron en aquellos años y que proclamaron: la igualdad jurídica entre peninsulares y ultramarinos, la libertad de prensa (el 5 de noviembre de 1810), la supresión de los viejos señoríos (el 1 de julio de 1811) y una serie de medidas desamortizadoras, en especial las referentes a la venta de los terrenos baldíos ya que convine recordar que $2 / 3$ de la superficie cultivable se encontraba en manos muertas; a todo ello cabe añadir que tras la aprobación del texto constitucional, las Cortes extraordinarias decretaron la desaparición de la Inquisición el 22 de febrero de 1813.

Además de reasumir estas disposiciones, la Constitución de 1820 se caracterizó por su arraigado carácter anticlerical y, como tal, suprimió de nuevo a los jesuitas el 17 de agosto, a la vez posibilitó el retorno de los afrancesados, 
que en número de 12000 aproximadamente pudieron regresar a la península, según la propuesta del diputado Moreno Guerra de 11 de julio de ese mismo año ${ }^{1}$. Esta actividad legislativa se mantuvo hasta julio de 1822 con la presencia en el poder de los gobiernos liberales que maniobraron entre las intrigas del rey y las contramanifestaciones de sus correligionarios más radicales; a partir de esa fecha gobernaron los militares radicales hasta la aniquilación de la España constitucional por la invasión francesa del duque de Angulema².

Centrándonos ya en el propósito fundamental de nuestro estudio resulta más que evidente y bien conocido en la actualidad el papel que adquirió la ciencia española durante la Ilustración. Desde entonces ésta asumió cada vez más el rol de una creciente implicación en la realidad del estado y la sociedad; sus motivaciones fueron más allá de lo estrictamente académico o cultural e influyó no sólo en el campo intelectual sino también en el social al incorporarse el hombre de la calle a la vida política. La ciencia que emergió en este período percibió la realidad nacional y persiguió, sobre todo desde mediados del siglo XVIII, una finalidad ideológica que además de estimular el reconocimiento físico del país permitió a sus protagonistas reflexionar sobre el pasado, convirtiéndoles de alguna manera en paladines de planteamientos innovadores con los que hacer frente a los cambios sociales que se avecinaban.

Bajo estas consideraciones, el examen de las actitudes y actividades políticas de los científicos españoles en el primer tercio del siglo XIX, durante el reinado de Fernando VII, presenta una gran novedad y ofrece un claro interés porque nos permite apreciar el esfuerzo y las dificultades en que se desarrolló su actividad profesional inmersa en la complicada trama política y social de la sociedad española de este período sombrío, caracterizado esencialmente por la persecución de liberales y afrancesados.

Sin embargo, pese a ser éste el factor dominante en la vida pública española y por tanto también muy determinante en el seno de la comunidad científica, como no podía ser de otra manera, se da la circunstancia de contar entre sus filas con grupos de científicos más o menos afines a esa ideología liberal, que

1 Para conocer este último aspecto puede consultarse los trabajos de Deleito Y PiÑUel.A, José: «La emigración política durante el reinado de Fernando VII» en Asociación española para el progreso de las ciencias (Congreso de Bilbao) I (1920); «La expatriación de los españoles afrancesados» en Nuestro tiempo (Madrid) 271 (1921) y «El regreso de los afrancesados a España en 1820» en Asociación Española para el Progreso de las Ciencias (Madrid) (1927).

2 - Para conocer las circunstancias que motivaron estos hechos durante el Trienio Liberal puede consultarse: COMELLAS, José Luis: Los realistas en el Trienio Constitucional (1820-23), Pamplona, Studium Generale, 1958; ARTOLA, Miguel, El Trienio Constitucional, Madrid, 1968: Historia de España, fundada por Ramón Menéndez Pidal, vol. 26, pp.671-841; FonTANA LÁZARO, José: La quiebra de la monarquía absoluta 1814-1820, Barcelona, Ariel, 1971; GIL NOVALES, Alberto: Las Sociedades Patrióticas (18201823), Madrid, Tecnos, 2 vols., 1975, Rafael del Riego. La revolución de 1820, día a día, Madrid, Tecnos, 1976.y El trienio liberal, Madrid, Siglo XXI, 1980; BARBASTRO GIL, Luis: Los afrancesados. Primera emigración política del siglo XIX español (1813-1820), Madrid, CSIC, 1993; LÓPEZ TABAR, Juan: Los famosos traidores. Los afrancesados durante la crisis del Antiguo Régimen (1808-1833), Madrid, 2001.

Hispania, LXIII/3, núm. 215 (2003) 1031-1056 
coexistieron con otros de tendencias opuestas y hasta con actitudes políticas enfrentadas. Unos fueron seguidores incondicionales del rey deseado - los absolutistas - y otros, quizás la mayoría, tuvieron una predisposición de clara oposición al régimen absolutista fernandino, rechazando en unos casos la figura real que encarnaba esta posición política y por tanto partidarios de José I - los afrancesados-, y los que, aunque con reticencias, aceptaron y defendieron a Fernando VII como rey constitucional - los liberales-.

En un primer momento muchos de los académicos e intelectuales de este período constituyeron un grupo más o menos homogéneo, educado en las instituciones científicas de la Ilustración, a los que cabría añadir, posteriormente, los que consolidaron su formación después de la guerra de Independencia y que desarrollaron su actividad científica más relevante tras el paréntesis bélico. Entre los que desde el principio se encuadraron en el bando bonapartista, muchos ocuparon cargos en las instituciones científicas dentro de la administración josefina (intendentes, prefectos, jefes de sección ministerial), unos de manera voluntaria y otros que se limitaron a permanecer en sus puestos de forma forzada o involuntaria; a este grupo habría que agregar a los que, dentro de este entramado, se incorporaron a la vida científica española tras el cese de hostilidades. Este es el caso, por ejemplo, del francés Pedro Alejandro Aubert que llegó a España con las tropas napoleónicas, formándose científicamente en Madrid como destacado naturalista. Estudió botánica en el Jardín Botánico, bajo la dirección de Boutelou en los años 1811 y 1812, zoología y mineralogía en el Museo de Historia Natural con los naturalistas Mociño y Herrgen respectivamente. En 1821 obtuvo la carta de ciudadanía española, pero su amistad con el general Lacy -fusilado en 1817- y con todos los constitucionalistas coruñeses, le obligó a emprender la huida una vez fracasado el intento de restaurar la monarquía constitucionalista en España ${ }^{3}$.

$\mathrm{Al}$ otro sector opositor, pero en bandos contrarios durante la contienda, pertenecieron científicos del grupo liberal, muchos de los cuales se encuadraron en los batallones patrióticos para combatir a los franceses y se inscribieron en el ejercito como ingenieros, marinos y sanitarios básicamente; en este último apartado se encuentra Mariano Lagasca, al que dedicaremos gran parte de nuestro trabajo durante el Trienio Liberal.

En el liberalismo de 1820-1823, la corriente moderada estaba representada por los liberales exiliados y los represaliados por el rey en 1814. Eran los hombres de 1812 - los doceañistas-, que atenuaron sus ímpetus de cambios por el duro golpe que sobre sus vidas representó el exilio y la cárcel. La revolución de 1820 permitió emprender nuevamente la política liberal de las Cortes de Cádiz, completarla con nuevas leyes y, lo que fue aún más importante, aplicarla a todo el país.

3 Puig-SAMPer, Miguel Ángel y VALERo, Mercedes: Historia del Jardín Botánico de La Habana, Madrid, 2000.

Hispania, LXIII/3, núm. 215 (2003) 1031-1056 
Inmersos en este complejo esquema político podemos encontrar personajes del mundo de la ciencia y de la cultura con una brillante trayectoria científica y profesional, que inequívocamente en un determinado momento se posicionaron en el bando progresista, encuadrados dentro del sector liberal y que tuvieron una especial influencia en el terreno de las ideas y de la vida política. A este grupo nos vamos a referir al describir la prácticamente desconocida participación política en las Cortes del Trienio Liberal de los botánicos Mariano Lagasca y Simón de Rojas Clemente, junto a otros relevantes científicos, como José Rodríguez, Felipe Bauzá o José MarianoVallejó.

Comprobaremos que la legislación de las Cortes influyó en la puesta en marcha de proyectos, reglamentos y normas sobre las innovaciones y reformas científicas, académicas y sociales del país, en las que intervinieron los botánicos Clemente y Lagasca. Dejaremos para otro momento la tarea de escudriñar exhaustivamente su labor como diputados y a modo de síntesis expondremos los aspectos recogidos en el Diario de las sesiones de Cortes, en el que figuran sus intervenciones y aparecen reseñados los decretos y órdenes del período considerado, si bien con relación y de forma comparativa a las mismas cuestiones de la obra legislativa de las Cortes de Cádiz.

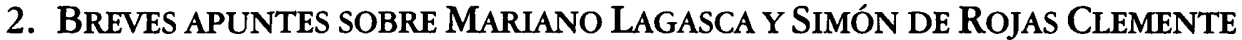

$\mathrm{Al}$ margen de los datos que conocemos sobre la vida y los trabajos botánicos de Manuel Mariano Lagasca (Encinacorva, Zaragoza, 1776 -Barcelona, 1839), que son más o menos conocidos ${ }^{5}$, aunque de manera un tanto difusa, nos proponemos abundar más en las penalidades que sufrió, la persecución de que fue objeto por parte de sus enemigos y su huida al exilio, aspecto muy relacionado con su actividad política durante su participación como diputado en las Cortes del Trienio Liberal.

4 Éstos y otros muchos figuran en: Gil Novales, Alberto (dir.): Diccionario biográfico del Trienio liberal, Madrid, 1991 y Ciencia e independencia política, Madrid, 1996. En los clásicos repertorios sobre las biografias de los científicos y la historia de la ciencia española, hemos consultado: LÓPEZ PIÑERO, José $\mathrm{M}^{\mathrm{a}}$, et al.: Diccionario bistórico de la ciencia moderna en España, Barcelona, 1983, dos vols.; Vernet, Juan: Historia de la Ciencia española, Madrid, 1975 y el recientemente aparecido: Maldonado Polo, J.Luis y García Gonzál.ez, Armando: La España de la Técnica y la Ciencia, Madrid, 2002.

s Álvarez LóPEZ, Enrique: «Notas sobre botánicos aragoneses. Con motivo de un homenaje» en Aanales del Instituto Botánico A.J. Cavanilles (Madrid) 18 (1969), pp.9-13; CARREÑO, Eduardo: "Notice sur la vie et les escrits du botaniste espagnol Dr. Mariano La Gasca» en Annales des Sciences Natureles (París) (septiembre de 1840), pp.1-16; REYES PRÓSPER, Eduardo: Estudio bio-bibliográfico de M. La Gasca y Segura. Madrid, 1917; RocamORA, Manuel: Estancia y fallecimiento del botánico La Gasca en Barcelona (1834-1839). Barcelona, 1955; CASASECA, B.: «La vida de La Gasca» en Lagascalia (Madrid) 6(2) (1976) pp.191-201; YÁÑEZ GIRONA, Agustín: Elogio bistórico de Mariano Lagasca y Segura, Barcelona, 1842. 
Sus ideas y pensamiento político se manifiestan en sus escritos y discursos y responden al porqué de su persecución por parte de la Inquisición, del clero retrógrado y del represivo sistema absolutista fernandino restablecido tras el regreso de Fernando VII en 1814. A la vez mostraremos algunas características de su acción política y corregiremos algunas opiniones que autores como Francisco Bellot apuntaron hace unos años en trabajos pioneros sobre esta faceta del botánico aragonés y que son errores evidentes a la luz de los datos que se desprenden de nuestras pesquisas ${ }^{6}$.

Mariano Lagasca es, sin duda, una de las figuras más atrayentes de la botánica española, símbolo de la unión fecunda de la agricultura y la ciencia. Su categoría científica fue reconocida fuera de nuestras fronteras y su fama mereció el respeto y la admiración de los principales intelectuales y científicos extranjeros, entre los que figuran el eminente De Candolle o el celebre Humboldt que, según parece, fue quien asesoró al gobierno de José I para que Lagasca dirigiese el Jardín Botánico de Madrid. Cuestión ésta que nos permite apreciar desde un momento temprano de su vida sus actitudes ideológicas y políticas, ya que su deber de patriota le impidió hacerse cargo, por el momento y durante este paréntesis histórico, de una institución tan prestigiosa que favorecía sus inclinaciones científicas.

Se fugó de Madrid en 1809 huyendo de la policía bonapartista e incorporándose a los ejércitos nacionales en los que se distinguió en el ejercicio de su profesión como médico, sin descuidar por eso la botánica para lo que aprovechaba las campañas militares para herborizar en las regiones que recorría. Finalizada la guerra sufrió la indignación y la calumnia de sus adversarios y aunque parezca mentira hubo de rehabilitarse ante el nuevo gobierno de Fernando VII, aceptando esta vez los puestos de responsabilidad que se le encomendaron. La Regencia del Reino le nombró interinamente primer catedrático y director del Jardín Botánico de Madrid, cargos que posteriormente le confirió el mismo rey en propiedad.

Desempeñó sus tareas con brillantez y continuó trabajando en sus dos obras preferidas, La Flora y la Ceres española, gracias a que logró formar una extensa red de correspondientes repartidos por toda la península; además en 1817 se le nombró, en pleno sexenio absolutista, Inspector General de los Plantíos y Arbolados del Canal del Manzanares.

Durante los años del Trienio es cuando su actividad política adquirió su punto más álgido. Colaboró, sin ser aún miembro del parlamento, con la Comisión de Instrucción pública de las Cortes de 1820 y 1821 en los ramos de medicina y ciencias naturales y contribuyó a la elaboración del proyecto que presentó la misma Comisión y que dio lugar a la aprobación de la ley de Instrucción pública de 29 de julio de 1821. A continuación, disueltas las Cortes

6 Bellot RodrígueZ, Francisco : «Lagasca como Político»en Lagascalia (Madrid) 6(2) 1976. pp.203-208.

Hispania, LXIII/3, núm. 215 (2003) 1031-1056 
extraordinarias el 14 de febrero de 1822, se procedió a elegir nuevos diputados y el 15 de febrero Lagasca es elegido diputado a Cortes por Aragón y Felipe Bauzá por Baleares ${ }^{7}$, aprobándose los poderes de ambos el 25 del mismo mes ${ }^{8}$.

Tras los lamentables sucesos de 1823, en que se inició la denominada "década ominosa», tuvo que huir a Sevilla, luego a Cádiz y a Gibraltar y pasar al exilio en Londres, donde llegó en 1824 y permaneció, tras una corta estancia en la isla de Jersey, hasta su repatriación diez años después, gracias a la nueva situación política que posibilitó que el gobierno español restableciera las libertades y concediera una amnistía a los presos y exiliados políticos. El regresó de Inglaterra lo hizo pasando por París, Lyón, Aviñón y Montpellier, llegando a Barcelona a finales de 1834. Después de un mes de estancia en la capital catalana llegó a Madrid para reincorporarse a las actividades del Museo de Ciencias Naturales y presidir la Junta de profesores que se encargó de la dirección y administración del centro científico?.

Por su parte el valenciano Simón de Rojas Clemente y Rubio ${ }^{10}$ (Titaguas, 1777 - Madrid, 1827) mantuvo una estrecha amistad con Lagasca desde 1800 en que ambos coincidieron como alumnos de Antonio José Cavanilles en el Jardín Botánico de Madrid, herborizando en los contornos de la capital y colaborando, desde entonces, en diversos trabajos científicos, como el referido sobre la Ceres Española y en publicaciones de variada temática, sobre todo de florística y botánica agrícola.

Tras su estancia en París y Londres en 1802, como paso previo para su proyectado viaje a África, junto al aventurero Domingo Badía - Ali Bey-, permaneció en Andalucía explorando las sierras de Granada y Ronda hasta octu-

7 Diario de sesiones (D.S), s.p.

8 D.S., pp.49-51. En adelante, como en este caso, especificaremos la página o páginas del Diario, cuando la información que en él figure se corresponda exclusivamente con la que nosotros incluimos en el texto. En caso contrario, cuando los datos extraídos del Diario excedan de los comentados, cuya discusión nos desviaría de nuestros propósitos, lo indicaremos sustituyendo la paginación por el número $\left(\mathrm{N}^{\circ}\right)$ del mismo, cuya fecha se corresponde exactamente con la que señalamos en los comentarios del texto y que antecede a las llamadas de las propias notas.

9 CASASECA (1976), opus cit.

10 RUBio HERRERO, Samuel: Biografía del sabio naturalista y orientalista valenciano Simón de Rojas Clemente y Rubio, Madrid, 1991; COLMEIRO, Miguel: La botánica y los botánicos de la península bispanolusitana, Madrid, 1858, pp.195-197; Simón de Rojas Clemente y Rubio y el segundo centenario de su nacimiento, Ayuntamiento de Titaguas, Valencia, 1977; Gil Albarracín, Antonio: «Vida y obra de Simón de Rojas Clemente Rubio» y CAPEL SÁEZ, Horacio, Gil AlBARRACín, Antonio: «Bibliografía» en: Clemente Rubio, Simón de Rojas: Viaje Andalucía. "Historia Natural del Reino de Granada" (1804-1809), Almeria-Barcelona, 2002, pp.47-82, 83-94; GIL AlBARRAcín, Antonio: Viaje al Cabo de Gata en 1805 por Simón de Rojas Clemente, Barcelona, 2002; LAGASCA, Mariano: «Biografía de D. Simón de Rojas Clemente» en Ocios de españoles emigrados (Londres) 7 (1827) pp.401-413; PARDO, Luis: «El testamento científico de Simón de Rojas Clemente y Rubio» en Boletín de la Sociedad lbérica de Ciencias Naturales (Zaragoza) IX (1927) y «Simón de Rojas Clemente y Rubio y el primer centenario de su muerte» en Anales des Instituto Nacional de $2^{a}$ enseñanza.. (Valencia) 15 (1827).

Hispania, LXIII/3, núm. 215 (2003) 1031-1056 
bre de 1805 en que regresó a Madrid para ocupar la plaza de bibliotecario en el Jardín Botánico y ejercer como redactor de los 6 últimos tomos del Semanario de Agricultura, que se editaba en el propio Jardín, hasta 1807 en que se suspendió la publicación.

En este mismo año se trasladó nuevamente a Andalucía, esta vez a San Lúcar de Barrameda, encargándose del jardín experimental que acababa de implantarse e impartir la docencia hasta que la invasión napoleónica dejó la escuela del jardín de aclimatación sin alumnos, por incorporarse éstos a la resistencia. Simultaneó su encargo como director del jardín de San Lúcar con sus exploraciones por la serranía de Ronda y la hoya de Málaga con el fin de completar sus observaciones sobre la historia natural del reino de Granada, centrándose en las mediciones geodésicas de Sierra Nevada, datos altitudinales que utilizó Humboldt para sus estudios sobre la topografía de la península ibérica. Durante esta época Clemente sufrió todo tipo de vejaciones y su vida corrió un serio peligro por las envidias y las bajas pasiones de sus enemigos que azuzaron al populacho en su contra.

Ocupada Andalucía por los franceses, regresó otra vez a Madrid. Se le ofreció reiteradamente una plaza en la Secretaría del Ministerio del Interior, puesto al que rehusó por no querer colaborar con el gobierno que entonces había en la capital, pero las dificultades bélicas y la absoluta escasez de recursos le impidieron poder continuar sus trabajos naturalistas, lo que le obligó a retirarse a su Titaguas natal en 1812 .

A los dos años se trasladó a Cádiz para integrarse en la Comisión del mapa topográfico nacional, por iniciativa de su director Felipe Bauzá, como naturalista de la misma, empresa que fracasó como tantas otras. Regresó nuevamente a Madrid para reincorporarse a su puesto de bibliotecario en el Jardín Botánico después de vencer las enormes trabas que le impusieron sus enemigos acusándole de afrancesado. Su carácter retraído e inseguro y su poca afición a la polémica le impedían tomar parte en partidos políticos y todo tipo de asociaciones, extremo éste que le llevó hasta a negarse a formar parte de la codiciada Sociedad Linneana de Londres, pero no obstante las Academias de Ciencias de Baviera, de Ciencias y artes de Barcelona, la Fisiográfica de Lund, la Real Sociedad de Agricultura del alto Garona, las Económicas de Madrid, Granada y San Lúcar y el Instituto militar Pestalozziano le incluyeron entre sus miembros.

Bien conocido por sus méritos y por sus ideas políticas, mereció ser nombrado diputado a Cortes por Valencia en las elecciones del 22 de mayo de 1820 permaneciendo en su escaño en el parlamento hasta el 14 de febrero de $1822^{11}$.

En la primera Junta preparatoria del 26 de junio de 1820 ya figura Rojas Clemente el primero de la lista de diputados por Valencia, sin que todavía existiera la Diputación permanente de las Cortes. Oficialmente juró, como diputado electo, la Constitución el 2 de marzo de 1821, al no poder hacerlo por enferme-

11 LAGASCA (1827) opus cit. 
dad el 25 de febrero del año anterior ${ }^{12}$ y en la legislatura de 1820 formó parte de las Comisiones de Agricultura, Código rural y Salud pública y en las de Agricultura, Industria y Artes y Minería de Nueva España, en la de 1821.

Por su quebrantada salud las Cortes el 2 de octubre de este último año, presididas por el Sr. Vallejo, acceden a la súplica de Clemente desde Titaguas, concediéndole licencia para que permanezca en esa localidad valenciana hasta su restablecimiento ${ }^{13}$. El 13 de diciembre nuevamente le conceden permiso para trasladarse a su pueblo enteradas del oficio que él mismo presentó manifestando su imposibilidad para asistir al Congreso por la enfermedad que subsistía $^{14}$. Finalmente en las Cortes extraordinarias el 14 de febrero de 1822, al proceder a las nuevas elecciones, Clemente dejó de ser diputado ${ }^{15}$.

\section{LA ACTIVIDAD PARLAMENTARIA DE CLEMENTE Y LAGASCA EN LAS CORTES. LEGISLATURAS DE 1820-1823}

La proclamación de la Constitución nuevamente en 1820 abrió otro período legislativo, en cuyo Congreso de diputados se formaron entre otras las ya citadas Comisiones de Agricultura, Industria y Artes, del Código Rural y la especial de Salud Pública, en las que de un modo u otro intervinieron Rojas Clemente y Lagasca, aunque este último aún no formaba oficialmente parte del parlamento como diputado electo.

En las siguientes legislaturas, tanto ordinarias como extraordinarias de 1821 y 1822, los dos botánicos y otros renombrados científicos como José Mariano Vallejo, José Rodríguez o Pablo de La Llave intervinieron directa o indirectamente, además de en esas comisiones, en las de Poderes, de Instrucción pública, de Legislación, la Eclesiástica, de Hacienda, del Código penal, de Ultramar, de Pesas y medidas, de Marina, y las especiales sobre Abolición del tráfico de esclavos, sobre el Fomento de la minería en Nueva España o la de Baldíos...En ellas se estudiaron y debatieron, básicamente, muchas de las reformas iniciadas que no pudieron llevarse a afecto en las Cortes de Cádiz junto a nuevos proyectos e iniciativas del momento.

En concreto el 2 de septiembre de 1820, las Cortes acordaron que una comisión especial de Salud Pública, de la que formó parte Clemente, estudiase el escrito presentado por el médico de Cádiz, Bartolomé Mellado y que leyó el Presidente Giraldo, sobre el origen y difusión de la epidemia de fiebre amarilla en las provincias meridionales de la península ${ }^{16}$.

\footnotetext{
12 D.S., s.p. y p.24, respectivamente

13 D.S., p. 74

14 D.S., p. 1245.

15 D.S., s.p.

16 D.S., p. 762.
} 
El 7 de noviembre, la misma comisión examinó la representación que hicieron a las Cortes, los catedráticos del Colegio nacional de farmacia de Barcelona, Agustín Yáñez y Raimundo Fors, sobre la conveniencia de suprimir el Protomedicato o Tribunal Supremo de salud pública por inconstitucional; igualmente en la misma sesión los diputados de la comisión estudiaron el recurso presentado por el Colegio de Cirugía de San Carlos ${ }^{17}$.

Dentro de este mismo apartado de sanidad e higiene, el 3 de marzo de 1822 se nombró a Mariano Lagasca y al también médico Mateo Seoane asesores de la citada comisión, no como miembros de hecho, por su fama como especialistas en la materia para examinar el proyecto de decreto sobre salud pública que se estaba debatiendo ${ }^{18}$. En las sesiones extraordinarias del uno y tres de mayo del mismo año, Lagasca intervino en la discusión del dictamen de la Comisión de Hacienda sobre el Presupuesto de la Secretaría del Despacho de la Gobernación de la Península, insistiendo en los apartados de salud pública, instrucción públi$\mathrm{ca}$, código sanitario, combate de epidemias... ${ }^{19}$. Al día siguiente continuaron los debates sobre el mismo asunto y Lagasca propuso «agregar su voto particular contrario a la resolución de las Cortes por la cual se aprobaron la parte del citado presupuesto en lo que dice relación con el ramo de salud pública» ${ }^{20}$.

No fue sino hasta la legislatura extraordinaria de 1822-1823 en la que tanto Lagasca como Seoane se integraron oficialmente como miembros de la comisión de salud pública. Esto tuvo lugar el 15 de octubre de $1822^{21}$ y, en el caso de Lagasca, el 5 de noviembre siguiente se produjo su juramento de la Constitución por no haberlo hecho en su día ${ }^{22}$. Después de esta formalidad Lagasca, ya como representante legal del Congreso, insistió en la necesidad de reformar la situación sanitaria, pero esta vez en relación con el ejercito. De manera que tanto el 19 de diciembre como el 1 de enero del siguiente año intervino en la discusión del proyecto del servicio de sanidad militar que en esos momentos se debatía dentro de la Comisión de guerra ${ }^{23}$.

$\mathrm{Al}$ margen de este tema sobre la sanidad nacional y de otros que más atrajeron la atención de nuestros botánicos como los que tenían que ver con la reforma agraria y la educación, que veremos más adelante, otros asuntos de interés parlamentario sobre cuestiones o aspectos de tipo institucional, industrial o económico también contaron con su participación.

En la sesión del 9 de mayo de 1821, Clemente, junto el matemático José Rodríguez, formó parte de la Comisión especial que debería informar sobre la propuesta, de 29 puntos, encaminada a fomentar la riqueza minera de Nueva

17 D.S. No 126.

18 D.S., p. 73.

19 D.S. $\mathrm{N}^{\text {os }} 74$ y 78.

20 D.S., p. 1185.

21 D.S., p. 177.

22 D.S., p. 485

23 D.S. $\mathrm{N}^{\text {os }} 78$ y 90. 
España $^{24}$. Igualmente, durante el siguiente año, Lagasca se ocupó de las cuestiones mineras y económicas en relación con los recursos naturales. De manera que el 12 de junio intervino en la discusión de la comisión de Visita del Crédito público sobre las minas de plomo y argumentaba al respecto: «mi objeto no ha sido tanto impugnar el artículo, como el hacer mis observaciones para aclarar el concepto de lo que parece ser más conveniente acerca de estas minas». A la vez indicaba la conveniencia de suprimir el párrafo que incluiría el acta de la sesión "hasta que las Cortes determinen...», lo que, según su criterio, podía significar el que algún día esas minas podrían ser enajenadas y él defendía su conservación y sostenimiento dada su utilidad ${ }^{25}$.

El 22 del mismo mes discutió el artículo $1^{\circ}$ del dictamen de la comisión de Hacienda sobre contribuciones a la renta de sal, que afirmaba entre otras cosas que «el estanco de la sal continuará como hasta aquí, pero reducido a las fábricas y salinas de la Hacienda pública, en las cuales venderá únicamente de cuenta de esta, al precio de 20 reales la fanega». Lagasca, contrariado con el argumento, manifestó que para acabar con el contrabando de la sal convendría bajar su precio, reduciendo de esta manera la codicia de los contrabandistas ${ }^{26}$.

Durante este año de 1822 del nuevo período legislativo, Lagasca recién elegido diputado, participó activamente en las sesiones parlamentarias de las Cortes. Su trayectoria profesional y su prestigio como hombre de ideas avanzadas y talante liberal le confirieron una personalidad singular. Su actuación en el hemiciclo, por estas consideraciones y otras de índole legislativo o de orden administrativo en las que también participó y que comentaremos a continuación, no pasó desapercibida, y se le eligió como uno de los representantes protocolarios del Congreso, afianzando y consolidando con su presencia el orden constitucional. En este sentido, el primero de marzo de ese año formó parte de la diputación establecida para recibir al rey; el cinco del mismo mes fue elegido para integrar el Tribunal de Cortes por 69 votos de un total de $97^{27}$ y al día siguiente intervino sobre el orden de lectura de las memorias de los respectivos ramos. Felipe Bauzá fue nombrado asimismo para la Comisión de Pesas y me$\operatorname{didas}^{28}$ y el 17. de marzo agregado a la Comisión de Marina ${ }^{29}$.

Además dentro de su faceta como legislador, al margen de sus intervenciones como hombre de ciencia, Lagasca participó el 28 de abril de 1822 en la comisión de Hacienda en relación con la discusión sobre incompatibilidades de funcionarios y sobre la rebaja de sueldos, ya «que podía suceder que algunos magistrados de la Audiencia u otros empleados fuesen nombrados Diputados a

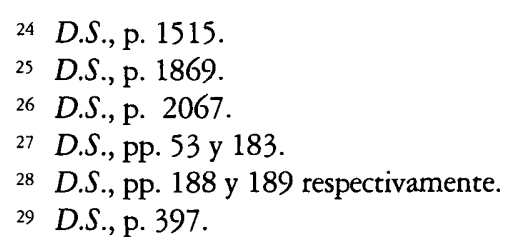


Cortes en cuyo caso debían proveerse interinamente aquellos destinos» ${ }^{30}$. Asimismo el 19 de junio le encontramos inmerso en la polémica que se generó en el parlamento acerca de las medidas propuestas por la comisión encargada de informar sobre el estado político del Reino «mediodía 25 reformada» ${ }^{31}$ y el 21 de noviembre en la comisión de legislatura, sobre la delegación especial encargada de rectificar la propuesta de visitador de Audiencia ${ }^{32}$.

Con anterioridad a estas actuaciones, el 19 de marzo de 1822 y en el mismo orden de ideas, parte de la ideología política de Lagasca se puso de manifiesto por su defensa, como aragonés que era, de la causa autonomista al reivindicar en un plano de igualdad el mismo trato respecto al resto de regiones españolas. En tal sentido intervino en la discusión del artículo $7^{\circ}$ del dictamen que se debatió en la Comisión de Premios, relativo a la erección de un monumento en Zaragoza, lugar donde fueron decapitados los tres héroes, Juan de Lanuza, Diego de Heredia y Juan de Luna, del mismo modo que se pedía para los castellanos Padilla, Bravo y Maldonado. Lagasca señaló que convendría tener presente si el lugar indicado $\left(\mathrm{Pz}^{\mathrm{a}}\right.$ de la Justicia) era suficientemente amplio para ensalzar la brillantez del monumento que recordaría la memoria de los paladines de la libertad aragonesa, en el día conmemorativo del «aniversario de la publicación de la Constitución política de la Monarquía»33.

Finalmente para concluir este capítulo de la participación de Lagasca en las distintas comisiones sobre la regularización y organización de la actividad parlamentaria, el 14 de febrero de 1823, en la última legislatura extraordinaria (1822-1823), se le nombró integrante de la diputación que debía informar al rey del día en que las Cortes extraordinarias finalizaban sus sesiones ${ }^{34}$.

\subsection{La agricultura y la reforma agraria}

Antes de adentrarnos en el papel que jugaron nuestros dos personajes en las Cortes del Trienio, centrado en los problemas de la agricultura y la reforma agraria que tan acalorados debates provocaron en el seno del parlamento, hagamos un breve inciso para repasar, aunque sea someramente, el estado de la cuestión antes del período que analizamos. Para ello, evidentemente tendremos que remitirnos a los tiempos de la primera época constitucional, y aún antes, donde la labor legislativa de las Cortes de Cádiz sobre esta problemática sentó las bases fundamentales para los cambios que acometió el Estado liberal a lo largo del siglo XIX.

\footnotetext{
30 D.S., p. 1043.

31 D.S. $\mathrm{N}^{\circ} 147$.

32 D.S. $\mathrm{N}^{\circ} 50$.

33 D.S., s.p.

34 D.S., s.p.
} 
La reforma de la propiedad de la tierra que se dio en casi toda Europa en el transcurso de la era preindustrial a la industrial también se produjo en España con la llamada desamortización, que permitió la introducción de mejoras técnicas y la expansión de la producción. La importancia del proceso desamortizador durante el siglo XIX en la consolidación de la actual estructura de la propiedad en España es un hecho incuestionable.

En esencia la desamortización, cuestión prioritaria para la reforma agraria, consistió en la incautación por parte del Estado (mediante compensación) de bienes raíces pertenecientes en su gran mayoría a la Iglesia y a los municipios. Estos bienes incautados (nacionalizados) fueron luego vendidos en pública subasta. La propiedad amortizada había sido objeto de muchas críticas por parte de algunos ilustrados del la España del XVIII, y sus ideas fueron recogidas y asimiladas por los grupos liberales del XIX, de tal modo que estos planteamientos constituyen el fundamento de su política. Los fundamentos desamortizadores pretendían facilitar la libre adquisición de tierras con la finalidad, de que con ello, la tierra cumpliese su función social y económica y, sobre todo, proveer a la Hacienda pública los fondos necesarios para cubrir el déficit presupuestario crónico.

De todos modos la ideología que sustentó la reforma agraria no presentó características ni mucho menos uniformes, ni sus instigadores se mostraron unánimes en sus posturas, sino que dependiendo de problemas concretos, las variantes fueron diversas para su resolución. A grandes rasgos el ideal reformista descansó esencialmente en el hecho de que los ilustrados albergaron en su seno dos grandes posiciones, germen de la historia económica y particularmente de la economía agraria. Por un lado los que pusieron su acento en los aspectos de la mejora agronómica o técnica y los que, aun reconociendo estas deficiencias, se empeñaron en denunciar los estorbos políticos, legislativos y hasta morales que la hacían impracticable.

Es bien sabido a este respecto que el Informe de Jovellanos explica que las graves limitaciones de la agricultura española procedían substancialmente, y aún continúan vigentes, de condicionantes políticos y sociales. El ilustrado asturiano achacó el estancamiento agrícola español a factores naturales y geográficos por un lado («estorbos físicos») y a factores sociales y culturales por otro («estorbos morales y políticos»). Sobre estos últimos pone su énfasis en la desigual distribución de la tierra en España desde tiempos remotos, en particular como consecuencia de la colonización que tuvo lugar durante la Reconquista.

Aunque no existen estadísticas precisas respecto al régimen de tenencia de la tierra, no es aventurado pensar que a comienzos del siglo XIX más de la mitad como mínimo de las tierras cultivadas pertenecían a la Iglesia y a la nobleza, vinculadas la inmensa mayoría a través de los mayorazgos y la amortización eclesiástica.

Los liberales españoles fueron herederos de la campaña regalista contra las manos muertas y de los ataques de los economistas a los mayorazgos que tan

Hispania, LXIII/3, núm. 215 (2003) 1031-1056 
aceradas críticas provocaron los ilustrados del XVIII. Sin embargo, en relación con la reforma de la agricultura y las medidas encaminadas para hacerla posible, conviene tener presente que los liberales de Cádiz, de un individualismo extremado, no se preocuparon prioritariamente de una redistribución socialmente aconsejable de la propiedad de la tierra, sino más bien del establecimiento de derechos de propiedad claros y absolutos en el más puro estilo del liberalismo económico de Adam Smith. Pero, no obstante, en lo referente a la política agraria, el complemento y culminación de las medidas de las Cortes de Cádiz deben verse en la reducción de los derechos que se pagaban al rey, a la iglesia o a los propietarios (diezmos), en el establecimiento de una contribución que subrogase las rentas provinciales, al igual que se había pretendido en Cádiz y en el comienzo de una desamortización.

En 1820 otra vez se recuperan los acentos puramente técnicos o agronómicos, que como al inicio del período ilustrado procedían de los botánicos, pero esta vez con científicos más especializados, más concienciados y mejor preparados para las tareas políticas dentro del marco constitucional que se desarrolló en las Cortes. Aquí es, por tanto, donde las iniciativas parlamentarias y los debates en las comisiones respectivas, así como las ocupaciones en tareas de índole burocrática o de gestión, tuvieron especial importancia para Lagasca en el primero de los casos y para Clemente más dedicado al segundo aspecto.

El botánico valenciano se integró en la Comisión de Agricultura que se formó en la Segunda Junta Preparatoria del 10 de julio de 1820 y continuó en la que se estableció el 2 de marzo del año siguiente con competencias en los ramos de Agricultura, Industria y Artes ${ }^{35}$; el 28 de agosto también se le eligió para la que debía encargarse de la formación del Código rural ${ }^{36}$. En lo que toca a Lagasca el Congreso le nombró miembro de las Comisiones de Agricultura y de Instrucción pública el 2 de marzo de 1822, junto a Bauzá en el caso de esta última, incorporándose además a la de Caminos y canales en esa misma fecha ${ }^{37}$.

La Comisión de Agricultura dictaminó sobre la repoblación de montes y baldíos y sobre el buen uso y aprovechamiento de los montes públicos, con la propuesta de revisión y reforma de las Ordenanzas de 1748, a la vez que se estimulaba el derecho de propiedad sobre la tierra para el campesino que trabajaba como base esencial del fomento de la agricultura. El cúmulo de medidas que se debatieron en la Comisión tuvieron su fundamento en el expolio sufrido por los pósitos de granos durante la guerra con Francia y las considerables pérdidas de cosechas del año de 1820 en Castilla la Vieja y León, lo que provocó la intervención del estado aportando grano para las simientes. En la misma Comisión también se discutieron y revisaron los múltiples decretos y ordenes que se habían proclamado en Cádiz y luego derogado tras el restablecimiento del

\footnotetext{
35 D.S., pp. 19 y 24 respectivamente.

36 D.S., p. 701.

37 D.S., pp. 55-56.
} 
absolutismo, lo que significó la plena anulación de las disposiciones abolicionistas del régimen señorial, las desamortizadoras, en especial aquellas que pretendían acabar con las prebendas eclesiásticas, o las que favorecían la libertad contractual sobre los arrendamientos.

La desamortización entró en vigor de nuevo en el Trienio Liberal, aunque no con los rasgos típicos que caracterizaron los de las desamortizaciones sucesivas del siglo XIX; es decir que se aplicó no como una reforma agraria clásica sino como una simple medida fiscal, que implicaba restablecer el equilibrio de la Hacienda pública en detrimento de la acción redistributiva de la propiedad tendente a favorecer a los campesinos pobres.

Lo mismo ocurrió con las disposiciones que se tomaron para establecer un régimen libre y abierto en los arrendamientos, que originó una oleada de protestas de los diputados durante la legislatura que transcurrió entre el 26 de junio y el 9 de noviembre de 1820, en la que se alegó la incongruencia de la tan cacareada libertad contractual en los arrendamientos en un país sin tierra libre para efectuar las transacciones comerciales. La libertad de contrato, en efecto, era incompatible con la supervivencia de la propiedad señorial, no obstante otras decisiones correctoras se pusieron en marcha. El 25 de octubre de ese mismo año se decretó sobre la reforma de regulares que disolvía o reducía la hegemonía de las casas de las ordenes monásticas, excepto las mendicantes ${ }^{38}$.

Las discusiones y polémicas debieron ser arduas y complejas por el clima social y político en que se desarrollaron. La política agraria del Trienio, al incurrir en las mismas faltas cometidas por los legisladores de Cádiz, agudizó las tensiones sociales en el campo y provocó la adhesión de grandes sectores del campesinado a las partidas absolutistas. Las libertades concedidas favorecieron a los ganaderos de la Mesta y provocaron la expulsión de muchos campesinos de las tierras que cultivaban. Lagasca intervino en estas y otras cuestiones que se debatieron en la correspondiente comisión de agricultura y, concretamente durante los días 8,14 y 15 de mayo de 1822 , lo hizo a propósito de la discusión que se produjo en torno a una exposición presentada por los ganaderos de Caspe, junto a otros temas relativos al ejercito ${ }^{39}$.

En este mismo orden de ideas, los días 13,20 y 27 de junio del mismo año se produjeron largas intervenciones de Lagasca en la discusión del dictamen y proyecto de la Comisión especial encargada de estudiar los decretos sobre repartimiento de baldíos y terrenos de propios. Decretos que tenían que ver con el que se promulgó el 4 de enero de 1813, mediante el cual se ordenaba la venta de la mitad de los terrenos baldíos o realengos reduciéndolos a propiedad particular plena y el reparto del resto de ellos y de propios, también en plena

\footnotetext{
38 Sobre estas cuestiones referentes a la política agraria y su legislación en las Cortes, tanto de la primera etapa constitucional como en el Trienio, puede consultarse: ANES, Gonzalo: «La agricultura española desde comienzos del siglo XIX hasta 1868. Algunos problemas» en Ensayos sobre la Economía española a mediados del siglo XIX (Madrid) (1970), pp. 235-262.

39 D.S. $\mathrm{N}^{\text {os }} 85,94$ y 95.
} 
propiedad, a los defensores de la patria de las guerras de la Independencia y las de las colonias, y a los vecinos que lo solicitasen y careciesen de tierras propias.

Los temas del proyecto que se elaboró en la Comisión eran de especial importancia para Lagasca y sus conocimientos acerca de la amplia problemática que abarcaba el mismo se pusieron de manifiesto en sus intervenciones, sobre todo en lo que tenía que ver con los artículos $4^{\circ}, 6^{\circ}$ del proyecto y las adiciones que propuso al $5^{\circ} .{ }^{40}$, por considerarlos como prioritarios sobre el resto.

Sobre el presupuesto del Despacho de Gobernación de la Península, de la Comisión de Hacienda, al que ya hemos aludido y sobre el que volveremos a insistir más adelante, Lagasca, el 1 de mayo de 1822, se refirió al código sanitario y anunció la próxima presentación por parte de la Comisión de Agricultura de un proyecto de ley sobre montes y plantíos. Cuestión también de gran interés para él y a la que dedicó grandes esfuerzos dentro de la legislatura extraordinaria de 1822-1823 por estar muy relacionada con su condición de naturalista y ser motivo de alarma y preocupación desde el punto de vista conservacionista, de modo y manera que desde el 22 de diciembre de 1822, Lagasca entró a formar parte de la comisión especial encargada de informar sobre el expediente de conservación de plantíos ${ }^{41}$.

Si embargo en este renglón legislativo, las ordenes y decretos no llegaron a poder traducirse en hechos concretos por la reacción absolutista subsiguiente. A pesar de su carácter individualista, rasgo típico del liberalismo decimonónico, tenían una marcada orientación democrática, pues destinaban gran parte de las tierras a la formación de lotes para los soldados y familias pobres, y por eso fueron muy bien recibidos por el pueblo, considerándolos como una medida que facilitaba el acceso de los trabajadores a la propiedad del suelo, tratando de conseguir de este modo la libertad económica, base indispensable de la política que las leyes le concedían.

En fin tras este ligero recorrido por los decretos, ordenes y proyectos innovadores en materia agrícola y sus posibilidades de transformación, en un clima a veces de duros enfrentamientos parlamentarios entre los diversos sectores del Congreso, en los que se vieron implicados tanto Clemente y más aún Lagasca, las Cortes del Trienio, pese a su talante reformista que favoreció en general el fomento agrario e industrial, herencia del espíritu ilustrado, se mostraron conservadoras en su mayoría y se caracterizaron por el proteccionismo en ambos sectores.

\subsection{La educación en las Cortes. Proyecto de Instrucción pública}

$\mathrm{Al}$ igual que en el tema de la agricultura y la reforma agraria, donde la presencia de nuestros botánicos tuvo su resonancia en las tareas legislativas, en el capítulo de la educación e instrucción pública su participación en los debates y

40 D.S. $\mathrm{N}^{\text {os }} 136,149$ y 162.

${ }^{41}$ D.S., p. 1102.

Hispania, LXIII/3, núm. 215 (2003) 1031-1056 
propuestas no fue menos importante. En este trascendental aspecto de los cambios estructurales que se acometieron durante el Trienio, la enseñanza y la instrucción pública, como también henos comentado para los asuntos agronómicos, tuvo en la ideología renovadora de Manuel José Quintana su más ferviente adalid. Además de su faceta como poeta, Quintana fue el inspirador principal de las reformas del sistema educativo español que se llevaron a cabo en las Cortes de Cádiz y luego en las del Trienio y también sirvieron de base a las que se establecieron tras la muerte de Fernando VII.

Sin embargo las propuestas y decretos que se pusieron en marcha en las Cortes gaditanas fueron derogados con el advenimiento del sexenio absolutista, pero su filosofía permaneció latente hasta 1820 en que de nuevo recobraron su vigor. Hasta que se puso en marcha un programa general de educación, los primeros meses del nuevo régimen mantuvieron de manera interina la enseñanza como estaba en 1814, es decir continuó estando vigente el plan de estudios de 12 de julio de 1807 y, mientras se elaboró el nuevo plan, se restablecieron centros y cátedras suprimidos durante los seis años anteriores. Esto ocurrió por ejemplo con los estudios de San Isidro o la Escuela de Ingenieros de Caminos; además se publicó el Reglamento sobre libertad de imprenta (decreto de 22 de octubre de 1820), se propagó el estudio de la Constitución por todas partes y se establecieron cátedras para su enseñanza.

El liberalismo postulaba el derecho de todo español a la educación, responsabilidad que debe recaer sobre la sociedad civil y encargarse a la vez de su propia planificación. La educación primaria, por consiguiente, será el centro de atención de la labor educativa del Estado y se convertirá en un instrumento político de primer orden.

Esto resultó muy evidente para Lagasca que, fuera del ámbito de las comisiones competentes en asuntos de educación, el 12 de junio de 1822 intervino en la formulación del artículo $3^{\circ}$ del proyecto de reglamento para la milicia nacional y facilitó algunos puntos de vista relativos al aprovechamiento de todo tipo de recursos para elevar el nivel de formación de los jóvenes soldados, argumentando «que convendría dejar en aptitud de poder servir a la Milicia Nacional a los militares que estuviesen en sus casas con licencia, pues ello podría producir muy buenos efectos por la mayor instrucción que prestarían a los individuos de la Milicia»"42.

El empeño de las Cortes en este renglón llega a reflejare en su capacidad receptiva ante las iniciativas de las clases profesionales que colaboran en el programa de renovación; prueba de ello son las memorias, opúsculos, ensayos etc., sobre planes generales de educación, reglamentos sobre centros particulares que fueron enviados al Congreso para que los diputados los tuvieran en cuenta en sus deliberaciones.

Un ejemplo de esto lo tenemos en el caso de Francisco Carbonell y Bravo, catedrático de química de la escuela establecida en Barcelona por la Junta na-

42 D.S., p. 1864. 
cional de Comercio de Cataluña, que en 1813 había publicado en Palma de Mallorca el Ensayo de un plan general de enseñanza de las ciencias naturales en Espa$\tilde{n} a$ dispuesto según los principios de la Constitución de 1812, en el que en su introducción elogiaba ese código político. El plan en cuestión lo remitió al Congreso de diputados, en atención a sus deberes de ciudadano para contribuir con ello a la cooperación con la comisión encargada de la instrucción publica en esas fechas. Sin embargo este plan de enseñanza no pudo discutirse en su momento por la disolución de las Cortes y quedar por tanto fuera de circulación, hasta que al ser reinstalado de nuevo el Congreso nacional en 1820 se puso de nuevo a disposición de los diputados y del público en general para su discusión y uso más conveniente ${ }^{43}$.

Desde el inicio, en el nuevo parlamento de las Cortes se fueron sucediendo distintas Comisiones de Instrucción Pública. En la primera de 1820 se elaboró el proyecto general de enseñanza pública que se presentó a la Cámara el 19 de octubre; en el correspondiente dictamen que acompañó al mismo se puso de manifiesto la identidad de planteamientos del de 1814 . El proyecto comenzó a discutirse el 23 de julio pero, debido a las modificaciones que introdujo la Comisión, se suspendió transitoriamente hasta su reanudación en las sesiones ordinarias y extraordinarias que desde octubre de 1820 se prolongaron hasta junio de 1821 en que se terminó su discusión y de cuyo proceso parlamentario surgió finalmente el Reglamento general de instrucción pública, según se expresa en el decreto copilatorio del 29 de ese último mes.

El 18 de marzo de 1821 durante su discusión, se pidió que se pusiese en marcha, sin esperar a la conclusión del proyecto en su totalidad, la enseñanza primaria y se estableciese la Dirección General de Estudios como organismo central, técnico y administrativo, según se estipulaba en la Constitución ${ }^{44}$. Aunque es cierto que en los debates iniciales del proyecto general de instrucción pública no pudo intervenir Mariano Lagasca por no ser miembro aún del Congreso, no es menos cierto que colaboró en los miembros del hemiciclo desde 1820, facilitando informes a la Comisión de Legislatura y, en este sentido, me voy a referir concretamente al que redactó para proporcionar unas «Observaciones» que posibilitasen la implantación del citado proyecto en los tres años siguientes. «Observaciones» que, además de ser materia de débate en el Parlamento, las expuso Lagasca en el discurso inaugural del curso que pronunció en el Jardín Botánico de Madrid el 9 de abril de 1821 y que contienen sus ideas y planteamientos políticos sin temor a la Inquisición y a las represalias de Fernando VII.

La falta de recursos materiales y financieros y la carencia de personal idóneo, que fueron los argumentos esgrimidos por los parlamentarios más pesimistas, también constituyeron la base de los razonamientos de su informe. A

43 «Aviso al público» en Diario de Barcelona, $\mathrm{n}^{\circ} 75$, de 19 de marzo de 1820, pp. 628-629.

44 BARGALló ARDÉVOL, Modesto: «Labor legislativa de las Cortes españolas de los años 18201823» en Asociación Española para el progreso de las Ciencias. Congreso de Sevilla (Madrid) 7 (1921) p. 11. 
diferencia de esos agoreros pusilánimes, sus reflexiones son extraordinariamente elocuentes y muestran al hombre animoso e ilusionado ante la nueva situación que se presentaba, que confía plenamente en el trabajo diario, en la capacidad y preparación de los científicos españoles y en los medios disponibles del momento para hacer viable el proyecto.

Ahora bien, todo ello bajo el control del Estado y su fiscalización por parte de las autoridades, para erradicar la corrupción y evitar las prebendas y favoritismos del poder, tan frecuentes en esa época y, por lo que podemos observar, también práctica habitual en nuestros tiempos.

Este planteamiento no indica, sin embargo, que Lagasca se muestre partidario de una absoluta centralización estatal, sino que haciendo gala de su condición liberal admite la libre empresa y la propiedad privada y reclama, por tanto, universidades particulares que estimulen y alienten a las oficiales. Se desprende de su argumentación, sin embargo, una concepción de la enseñanza netamente de carácter clasista, elitista y minoritaria, sobre todo para el grado superior o universitario, lo que por otro lado resulta de vigente actualidad en nuestros días. No obstante, y también de la misma manera que ahora, además de preservarse los mejores colegios para los más pudientes, todos los españoles tendrán obligatoriamente una enseñanza elemental y una media y superior, en la que prevalezca el criterio de favorecer a los más dotados; cuestión ésta última, que a mi entender y tanto en su época como en nuestros tiempos, es ilícita, injusta y de un utilitarismo improcedente, dado que las valoraciones de las categorías intelectuales humanas siempre resultan difíciles de valorar con ecuanimidad y ponderación.

La posición de Lagasca era ciertamente realista y plausible, si tenemos en cuenta que con la política de desamortización de los bienes eclesiásticos sería más que suficiente para disponer de suficientes universidades y centros educativos, muchos de los cuales se establecerían en los conventos suprimidos, de manera que sería factible implantar las tres grados de la educación sin necesidad de nuevos edificios y de incrementar desorbitadamente los recursos. Recuérdese a este respecto que había más de 3000 conventos y monasterios en esa época, si bien es cierto que los malos hábitos de sus regidores conducían a que la enseñanza resultase caduca e impropia de un país que tendía a instalarse en la modernidad de su tiempo.

Para el botánico aragonés la supresión de cátedras inoperantes y el excesivo peso de la teología en la formación llevaba al estancamiento y la pasividad. La renovación e instalación de nuevas materias como las ciencias aplicadas a la agricultura, la física o la química serían convenientes y regeneradoras del lamentable estado de la ciencia y contribuiría al desarrollo de España. Por consiguiente insistió en la enseñanza de las ciencias naturales como tema preferente, en el que la investigación aplicada y en la docencia de sus materias afines, tan en boga en esa época. Su adecuada implantación en muchos de esos conventos que disponían de grandes huertas y terrenos adyacentes, que se podrían recon- 
vertir en jardines botánicos o escuelas de experimentación agrícola, impulsarían de forma notable la botánica y la agronomía ${ }^{45}$.

Más adelante, el 29 de junio de 1821, las Cortes aprobaron el Reglamento general de instrucción pública que implantó la enseñanza en todos sus grados: primaria, secundaria y universitaria. Dividido en trece títulos disponía las bases generales de la enseñanza, cuya doctrina, ironías de la vida, parece sacada del futuro en el que nos encontramos y es la tabla de salvación de los políticos que con tanta elocuencia y grandes dosis de demagogia surten los programas académicos actuales: el carácter obligatorio y gratuito de la enseñanza primaria, la libertad de cátedra, la unitariedad de los estudios y los exámenes ante un tribunal de profesores de centros públicos, proscribiendo las oposiciones como única forma de acceso al profesorado.

En este Reglamento se sintetizan las ideas de las Cortes acerca de la educación y sirvió de base orientadora, al igual que el ya comentado sobre la reforma agraria, para las sucesivas modificaciones legislativas que en esta materia se realizaron a lo largo del XIX. Actualizó los planteamientos de Quintana, sobre todo en lo que se refería a la enseñanza media; él fue el primero que habló por primera vez de segunda enseñanza en España. Estos estudios deberían cursarse en las Universidades de provincias, creándose cátedras de ciencias, letras y artes, y entre ellas, la de mineralogía y geología, la de botánica y agricultura y la de zoología ${ }^{46}$. Como consecuencia de esta determinación, el 18 de abril de 1822, Felipe Bauzá, en la Comisión de Instrucción pública de esta legislatura, participó en la discusión sobre el expediente promovido por el Ayuntamiento de Vergara para que asignaran 120.0000 reales anuales al Seminario, según se había decretado en 1815 para dotación de cátedras y creación de una universidad de segunda enseñanza ${ }^{47}$.

Con anterioridad a la aparición del citado Reglamento de 1821, pero dentro de la misma legislatura donde se debatía el asunto, aparecieron producciones legislativas, ordenanzas, preceptos e iniciativas de gran trascendencia, relacionadas con la enseñanza superior y las tareas de sobresalientes científicos que por sus cualidades y conocimientos podían estimular y mejorar la reinstalación de vetustas instituciones científicas. El 14 de marzo de ese año «las Cortes mandaron pasar a las comisiones reunidas de Legislación e Instrucción pública una exposición dirigida al rey por la Junta de Protección del Museo de Ciencias Naturales, en la que se recomendaba el mérito distinguido del Sr. Diputado D. José Rodríguez, nombrado por el gobierno en 1819 director del Observatorio astronómico. Se informaba de la aptitud del mismo para que se le encargase de

45 LAGASCA, Mariano: «OBSERVACIONES SOBRE LA POSIBILIDAD de poner en planta dentro de tres años el proyecto de instrucción pública, presentado a las Cortes por su comisión en la legislatura de 1820" en Memorias de Agricultura y Artes, que se publican de orden de la Junta nacional de gobierno del comercio de Cataluña (Barcelona) 12 (1821) pp. 197-208 y 241-254.

46 RUIZ BeRrIO, Julio: La política escolar de España en el siglo XIX (1808-1833), Madrid, 1970, pp. 26-29.

47 D.S.,pp. 894-895.

Hispania, LXIII/3, núm. 215 (2003) 1031-1056 
nuevo de dicha dirección, sin otro sueldo que el que gozaba en ese momento como profesor de astronomía y con la misión de componer el Calendario y dirigir la obra material del mismo Observatorio. El gobierno, según oficio del Secretario del Despacho de la Gobernación que acompañaba la exposición, estimaba útil y ventajoso que el referido Sr. Rodríguez se encargase de dicho establecimiento, bajo el supuesto de que siendo su comisión puramente científica, no resultase incompatible con el carácter del Diputado» ${ }^{48}$. El mismo Rodríguez, el 9 de junio, intervino en los debates de la Comisión competente de ese año sobre el artículo 73 del título VI del proyecto general de Instrucción pública, referente a la Universidad Central. Además la Comisión de Legislación e Instrucción pública aceptó la iniciativa de la Junta de Protección del Museo de Ciencias Naturales para que el diputado José Rodríguez se reincorporase como director del observatorio Astronómico tal y como se sugería ${ }^{49}$.

Después de todo lo comentado sobre la cuestión educativa en las Cortes, quizás la medida de mayor importancia en la reorganización universitaria que se adoptó en el Congreso fue la que se tomó respecto a la creación de la Universidad Central de Madrid, en la que, tras su apertura, ejercieron como catedráticos Lagasca, Vallejo, Rodríguez y la mayor parte de los científicos del momento. La Dirección General de Estudios al crear esta universidad tuvo como objetivo principal el que esta Universidad Central sirviera de «escuela normal» para las demás universidades, cuestión que Lagasca ya había anticipado unos meses antes de su establecimiento en la Comisión de Hacienda durante el debate de los presupuestos. En la nueva Universidad se aumentaron las asignaturas a impartir respecto a las demás universidades de provincias y se fundían en ella las enseñanzas procedentes del Colegio Imperial y las del Museo de Ciencias Naturales. Su ampliación, en el terreno de las ciencias naturales, supuso establecer dos cátedras de zoología, una de anatomía comparada, dos de botánica, una de agriculturà experimental y dos de mineralogía.

\subsection{La botánica-agrícola. Enseñanza de la agricultura}

Con el ánimo de subsanar los problemas sociales que surgen al comienzo del siglo XIX, los políticos y economistas consideraron que mediante una enseñanza bien dirigida, con unos programas extensos y especializados, con una orientación profesional especializada, se podría arreglar en buena parte la crisis económica, sobre todo la agrícola e industrial, fuente de todos los males que padecía España.

La idea de crear en los pueblos principales, o al menos en todas las capitales de provincia, Escuelas Prácticas de Agricultura como modo de extender la en-

48 D.S., p. 59.

49 D.S. $\mathrm{N}^{\circ} 102$. 
señanza agrícola a toda la península procedía de Antonio Sandalio de Arias, que como agrónomo y principal promotor de esta formación durante el primer tercio del siglo XIX en España, vinculaba su docencia con las Sociedades Económicas de Amigos del País desde 1809, fecha en la que prestaba sus servicios al gobierno de José $\mathrm{I}^{50}$.

Los principios fisiocráticos que eran la piedra angular de esta disciplina fueron recogidos y asimilados por muchos de sus contemporáneos que, como Clemente o más aún Lagasca, tuvieron una influencia decisiva en el desarrollo de sus trayectoria científica. Sin embargo la idea de que la educación era un medio importante para difundir los avances de los nuevos métodos agrarios pasó a un segundo plano para los políticos del Trienio. Para ellos, esta formación quedaba supeditada a los cambios políticos previos, lo que acarreó intensas diatribas y polémicas en las Cortes.

La revolución económica, a través de la puesta en marcha de una serie de leyes y decretos que perseguían la supresión de la vinculación de la tierra, la desamortización de propios y baldíos, la desamortización eclesiástica y la reducción del diezmo a la mitad, fue la tarea prioritaria para los liberales. La enseñanza agrícola ayudaría al desarrollo del sector pero de manera secundaria.

De acuerdo con los precedentes de Cádiz y las iniciativas de Sandalio de Arias, el 5 de junio de 1820, se expuso el proyecto de ley a las Cortes para establecer escuelas prácticas de agricultura y economía rural. La Comisión de las Cortes que estudió el plan, tan sólo hizo una serie de objeciones a los presupuestos destinados a este renglón y su resultado fue que la enseñanza de la agricultura se incluyera en el Reglamento de Instrucción pública ya comentadosi.

Bajo estas circunstancias y con las misma preocupación por el fomento del desarrollo agrario español, el botánico catalán Juan Francisco Bahí, el 15 de febrero de 1821, presentó una Memoria exhortando a las Cortes sobre la necesidad de promocionar los estudios botánicos y de agricultura. En su parte final expuso las razones que le impulsaron a dirigirse a las Cortes, comentando que «lejos de mi el pensar instruirlas, si sólo indicar unas ideas que hace años abrigaba en mi seno para bien de mi amada patria: justo era que en esta feliz época de la libertad de hablar las pronunciase: lo hago sin el pincel de la elocuencia, pero con la franqueza que me caracteriza, y la sencillez y naturalidad de la cosa rústica de que trato: las Cortes, a cuya sabiduría y tino las sujeto, sabrán guardarlas»"52.

so MISAS JIMÉNEZ, Rolando: «Un promotor de la enseñanza agrícola desde la Real Sociedad Económica Matritense: Antonio Sandalio de Arias (1809-1820)» en Asclepio, 48 (1) (1996) pp. 101-121.

51 Montagut CONTRERAS, Entique: «La enseñanza de la agricultura en España en la crisis del Antiguo Régimen» en Torre de los Lujanes (Madrid) nº 40 (1999) pp. 197-245.

52 BAHÍ, Juan Francisco: «DE LA TRASCENDENCIA PUBLICA Y SUMA utilidad de ganar curso en las escuelas de botánica y agricultura los matriculados en facultad mayor» en Memorias de Agricultura y Artes que se publican de orden de la Junta Nacional de Gobierno del comercio de Cataluña, (Barcelona) Tomo 12 (meses de enero y mayo de 1821) p. 194.

Hispania, LXIII/3, núm. 215 (2003) 1031-1056 
Pretendía que esa formación científico-técnica se convirtiese en requisito obligatorio para poder comenzar los estudios en cualquier facultad universitaria y destinada especialmente para curas, jueces, médicos y farmacéuticos, quienes deberían haber aprobado previamente un curso de economía rural en escuelas de botánica y agricultura. Consideró, por tanto, que con el auxilio de las ciencias naturales, en concreto de la botánica, se conseguiría el rigor imprescindible en el estudio de la agricultura y elevarla al rango de una ciencia más.

La Comisión de Agricultura, en la sesión del día 13 de mayo de ese mismo año, se posicionó en favor del aprovechamiento de algunos monasterios donde impartir la enseñanza teórico-práctica de la agricultura y, sin contravenir lo aprobado ya por las Cortes en su plan de enseñanza, se podrían obtener fondos públicos para las fincas y edificios de comunidades suprimidas. También la Comisión abogó por el establecimiento de la enseñanza de botánica y agricultura en Madrid, primero en el Museo de Ciencias Naturales, es decir en el Jardín Botánico y luego en la Universidad Central.

Sin embargo y pese a que en el Jardín Botánico ya funcionaba la Cátedra de Agricultura desde 1815, pero dada su escasa superficie e insuficiencia de instalaciones adecuadas para la formación de alumnos en estas materias, la Comisión creyó conveniente que se agregasen los terrenos del huerto de los Jerónimos y el edificio del suprimido monasterio, colindantes al propio Jardín. El parlamento recibió con expectación estas alegaciones pero rechazó la anexión sugerida y se opuso al dictamen de la Comisión ${ }^{53}$.

Rojas Clemente, que como sabemos formaba parte de la Comisión de Agricultura en esta legislatura de 1821, no parece que tuviera un gran protagonismo en los debates, a pesar de que afectaba muy directamente a la institución científica de la que dependía. Sin embargo, el 7 de junio, intervino en la discusión del artículo 57 del proyecto de Instrucción pública, relativo al establecimiento de jardines de aclimatación en España. Argumentó al respecto que si bien estos debían establecerse en Andalucía, no era conveniente que se instalasen ni en Córdoba ni en Granada como se proponía, sino en San Lúcar de Barrameda por su mejor clima y tipo de suelo y alegaba, además, la existencia en esta localidad de un establecimiento de características semejantes.

Junto a Clemente, el botánico mexicano, residente en España, Pablo de la Llave también intervino sobre el mismo punto, pero en este caso, poniendo su énfasis en la existencia de una única escuela de agricultura en México, lo que resultaba claramente insuficiente para conseguir los fines que se perseguían no sólo en la metrópoli sino también en las colonias ultramarinas ${ }^{54}$.

53 D.S. $\mathrm{N}^{\circ} 75$.

${ }_{54}$ D.S. $\mathrm{N}^{\circ} 100$. Sobre las actuaciones como diputados en las Cortes españolas, en esta y en la anterior etapa constitucional, de este interesante botánico criollo, junto a otros dos botánicos también americanos, el neogranadino Francisco Antonio Zea y el quiteño José Mejía Lequerica, puede consultarse: MALDONADO POLO, J.Luis: "Científicos americanos en las Cortes constituyentes. La cuestión americana» en Revista de Indias (Madrid) 63 (N227) (2003) pp. 275-301. 
El 7 de julio nuevamente Clemente volvió a insistir sobre el mismo artículo en defensa de la agricultura experimental y el establecimiento de escuelas especiales en siete provincias españolas 55 .

En las sesiones extraordinarias de los días 1 y 2 de mayo de 1822 se producen las intervenciones de Lagasca en la Comisión de Hacienda, y a la que ya hemos aludido, en la que se discutió, dentro del debate de los presupuestos del Despacho de Gobernación de la Península, ésta y otras cuestiones. Los temas de la enseñanza en general y de las ciencias naturales y materias afines en particular, fueron el principal objetivo de sus comentarios. En el mismo sentido se volvió a pronunciar Lagasca en la sesión del 12 de diciembre de la siguiente legislatura extraordinaria, dentro de la Comisión de Comercio, sobre el dictamen de arbitrios consulares, en el que incluyó dos adiciones en orden a proporcionar medios para la instrucción pública... ${ }^{56}$.

Sus argumentos en todos los casos versaron sobre la escasez del presupuesto para la recolección de objetos de historia natural, sobre la enseñanza de la botánica... y acerca de los temas que afectaban al funcionamiento del Jardín Botánico de Madrid. Planteó así mismo, junto a varios asuntos relacionados con los fondos del proto-albeirato y los dedicados a la partida de libros, la necesidad de discutir la memoria de la Dirección General de Estudios, en la que debería incluirse la creación de una escuela normal, propuesta esta última de gran trascendencia para el sistema educativo. Aparte de estas observaciones, por faltar algunos de estos aspectos en el presupuesto que para él eran de gran importancia, consideró que éste no se debería aprobar ${ }^{57}$.

Junto a todo este compendio de problemas y cuestiones sin resolver de forma adecuada, y que no satisfacían las expectativas de Lagasca, se puede añadir que el deplorable estado de la Hacienda pública entorpeció, asimismo, la puesta en funcionamiento de su proyecto que había anunciado en la Comisión de Agricultura sobre la ley de montes y plantíos, e hizo hincapié en que las partidas dedicadas a la enseñanza durante el año económico de 1820-21 se englobaran en el presupuesto del Ministerio de Gobernación.

En estos discursos de Lagasca, prácticamente dos años después de sus Observaciones... sobre el proyecto de Instrucción pública, sus apreciaciones cambiaron substancialmente de sentido. Ahora sus críticas son más agrias y su optimismo inicial parece resentirse ante las circunstancias adversas por las que atraviesa el país, la miseria es la traba principal del plan, pero también lo son la falta de personal idóneo y la carencia casi absoluta de textos y obras elementales. Expresa que «una de las principales causas por que ha progresado tan poco en muchos ramos la juventud que se ha dedicado o instruirse en ellos, a pesar de su mucha aplicación, ha sido la falta de libros». Se queja de que no haya libros

\footnotetext{
ss D.S., p. 2115.

56 D.S. N 78.

57 D.S. $\mathrm{N}^{\circ} 74$.
} 
en las bibliotecas, y de que los pocos que hay en España estén impresos fuera. Para conseguirlos, es necesario hacer gastos que no todos pueden soportar y prosigue diciendo « a mi me cuesta cada tomo en $8^{\circ}$, de 400 páginas, de muy mala impresión, en pésimo papel y sin tener láminas, 100 rs., puesto en $\mathrm{Ma}$ drid " $\$ 8$. A este respecto cabe indicar que el 20 de septiembre de 1820 , la Comisión de Instrucción Pública ya proponía la revisión de los textos que deberían seguirse en las distintas universidades ${ }^{59}$.

El 2 de mayo de 1823, ya en las sesiones de Cortes que se celebraron primero en Sevilla y luego en Cádiz, obligadas por las circunstancias a este retiro de la capital después de la destitución temporal del rey por el gobierno radical, la Gaceta española se hizo eco de la noticia de que en la sesión del día anterior, reunida en Sevilla bajo la presidencia de Flores Calderón, se nombró a Felipe Bauzá vicepresidente por 68 votos del total de 106 y como presidente de las Cortes a Joaquín Ferrer ${ }^{60}$ y el 20 de junio, esta vez ya en Cádiz, en la sesión del día 19, las Cortes concedieron permiso a Lagasca para que pudiese pasar a Sevilla a fin de rescatar una parte de los manuscritos y libros preciosos que perdió en el saqueo de los equipajes durante su precipitada huida ${ }^{61}$.

El gobierno francés, ante el temor de una revolución similar a la de 1789 y a petición de Fernando VII y con el beneplácito de la Santa Alianza, envió un ejercito a España para ahogar cualquier atisbo de liberalismo. El 7 de abril de 1823 el duque de Angulema cruzaba la frontera francesa con un ejercito de 100.000 hombres, entre el aplauso y la satisfacción de la nobleza, el alto clero y la estupefacción de un pueblo perplejo e impotente. A partir de entonces se inició una feroz persecución contra los liberales que en el caso de los científicos e intelectuales sería dramática. Se suprimieron los periódicos, excepto el órgano oficial, La Gaceta de Madrid, se cerraron las universidades y se llevó al exilio a Marino Lagasca, a Casiano del Prado, a José Rodríguez, a Gabriel Ciscar, entre muchos otros ${ }^{62}$.

En definitiva y como colofón dedicaremos unas líneas para indicar el papel desempeñado por los dos diputados, y tal vez los mejores botánicos del primer tercio del siglo XIX, en las Cortes del Trienio Liberal, en un intento de superar la imagen tópica que se tiene del científico encerrado en su «torre de marfil», ajeno por completo a las preocupaciones de la sociedad de su tiempo.

Clemente no fue un político convencional y sus ideas fueron las de un liberal moderado. Defendió la libertad y votó siempre en este sentido, sin embargo

\footnotetext{
58 Ibid.

59 RUIz Berrio (1970), opus cit., p. 55.

60 D.S., p. 41.

61 D.S., p. 249.

62 Sobre el exilio español tras el final del Trienio, en el que se incluyen numerosas referencias a los intelectuales y científicos españoles que fueron víctimas de este desgracio episodio, es obligado mencionar la clásica obra: LLORENS, Vicente: Liberales y románticos. Una emigración española en Inglaterra, 1823-1834, Madrid, 1968, $2^{\mathrm{a}}$ ed.
} 
parece que su escasa relevancia en las Cortes, hace pensar que la vida política nunca fue de su agrado. Su participación no fue ni muy asidua ni brillante como cabría esperar de un hombre de su talento y su labor se concentró en el trabajo modesto de las diversas comisiones de la Cámara, procurando evitar sus intervenciones en discursos y debates en las sesiones plenarias. Tal vez, como indica su colega Lagasca, esta falta de esplendor se debiese a su delicada salud, al vómito negro que le perseguía desde tiempo antes que se restableciera la Constitución de 1820 y que finalmente sería la causa de su muerte ${ }^{63}$.

Lagasca, por el contrario, se mostró más activo durante sus intervenciones parlamentarias, esforzándose por consolidar las instituciones surgidas durante el Trienio y fortalecer la alta cámara legislativa, lo que le confiere poder ser considerado como un claro defensor del orden constitucional y ferviente partidario del cambio político producido tras el levantamiento de Riego. De su participación en las Cortes se aprecia el nada despreciable esfuerzo que realizó en sacar adelante sus ideas sobre la desamortización de los bienes eclesiásticos y por hacer entender a sus colegas diputados el valor y el significado de la ciencia y la educación. Contribuyó con sus conocimientos de medicina y ciencias naturales a la redacción de proyectos, dictámenes, ordenes y decretos y desempeñó cumplidamente sus compromisos con el Congreso, en medio de circunstancias difíciles. Su personalidad política como buen liberal resulta evidente a la luz de sus intervenciones, en las que manifiesta reiteradamente su preocupación por la corrupción y el nepotismo, en una época que muestra bastante similitud con la actual. El 26 de junio de 1839 falleció el ilustre botánico en Barcelona, su Ayuntamiento constitucional le homenajeó durante las exequias como obsequio a su mérito y reputación.

63 LAGASCA (1827), opus cit.

Hispania, LXIII/3, núm. 215 (2003) 1031-1056 